\title{
Alchornea glandulosa Ethyl Acetate Fraction Exhibits Antiangiogenic Activity: Preliminary Findings from In Vitro Assays Using Human Umbilical Vein Endothelial Cells
}

\author{
Flávia Cristine Mascia Lopes, ${ }^{1}$ Ana Rocha, ${ }^{2}$ Ana Pirraco, ${ }^{2}$ Luis O. Regasini, ${ }^{3}$ Janaina R. Siqueira, ${ }^{3}$ \\ Dulce H.S. Silva, ${ }^{3}$ Vanderlan S. Bolzani, ${ }^{3}$ Iracilda Z. Carlos, ${ }^{4}$ and Raquel Soares ${ }^{2}$ \\ ${ }^{1}$ Hematology and Hemotherapy Center, School of Medical Sciences, University of Campinas (UNICAMP), São Paulo, Brazil. \\ ${ }^{2}$ Department of Biochemistry (U38/FCT), Faculty of Medicine, University of Porto, Porto, Portugal. \\ ${ }^{3}$ Department of Organic Chemistry, Araraquara Institute of Chemistry; ${ }^{4}$ Department of Clinical Analysis, Faculty \\ of Pharmaceutical Sciences of Araraquara; São Paulo State University (UNESP), Araraquara, São Paulo, Brazil.
}

\begin{abstract}
Alchornea glandulosa has traditionally been used in Brazilian folk medicine for the treatment of immuneinflammatory diseases and as an antiulcer agent to heal gastric ulcer and gastritis. Angiogenesis is a complex multistep process that consists of proliferation, migration, and anastomosis of endothelial cells and has a major role in the development of pathologic conditions, such as inflammatory diseases. To investigate a possible link between the anti-inflammatory activities and antiangiogenic effects of A. glandulosa ethyl acetate fraction (AGF), this study examined which features of the angiogenic process could be disturbed by this fraction. The antiangiogenic activity of AGF was determined in vitro by using human umbilical vein endothelial cells (HUVEC), and cell viability, proliferation, apoptosis, invasion, and capillary-like structures formation were addressed. To elucidate the mechanism of action, nuclear factor $\kappa \mathrm{B}(\mathrm{NF} \kappa \mathrm{B})$, a transcription factor implicated in these processes, was also evaluated in HUVEC incubated with AGF. A significant decrease in proliferation, a relevant increase in apoptosis, and a strong reduction in invasion capacity (as assessed by bromodeoxyuridine, terminal deoxynucleotidyl transferase-mediated deoxyuridine triphosphate nick-end labeling, and double-chamber assays, respectively) were observed. AGF also led to a drastic reduction in the number of capillary-like structures formed when HUVEC were cultured on growth factor-reduced Matrigel-coated plates. In addition, incubation of HUVEC with AGF resulted in reduced $\mathrm{NF} \kappa \mathrm{B}$ activity. These findings emphasize the antiangiogenic potential of AGF and support its therapeutic use for disorders that involve excessive angiogenesis, such as chronic inflammation and tumor growth.
\end{abstract}

KEY WORDS: • Alchornea glandulosa • antiangiogenic $\bullet$ ethyl acetate fraction $\bullet$ human umbilical vein endothelial cells - nuclear factor $\boldsymbol{\kappa B}$

\section{INTRODUCTION}

$\mathbf{L}$ OCAL AND TRADITIONAL KNOWLEDGE has been the starting point for many successful drug development projects over the past decades. ${ }^{1}$ Brazil is a country of ethnopharmacologic interest because of its great cultural and biological diversity. ${ }^{2}$ The genus Alchornea belongs to the Euphorbiaceae family, which contains about 7,500 species, including trees, shrubs, and herbs, in all parts of the world. This family is economically important, providing food, rubber, medicines, oils, dyes, and many other useful products. ${ }^{3}$ Alchornea species are present in the South and Southeast Atlantic Forest and in the Amazon rainforest in Brazil. ${ }^{4,5}$

A. glandulosa Poepp. \& Endl. (Euphorbiaceae), a tree 10 20 meters tall, is known as tapiá. It has traditionally been

Manuscript received 5 August 2010. Revision accepted 30 December 2010.

Address correspondence to: Flávia Cristine Mascia Lopes, Hemocentro, Rua Carlos Chagas, 480, Ciudade Universitária, Barão Geraldo, Campinas 13083-970-SP, Brazil, E-mail: fcmlopes@yahoo.com.br used in Brazilian folk medicine for the treatment of immune-inflammatory diseases and as an antiulcer agent to heal gastric ulcer and gastritis, with confirmed antiinflammatory activity. ${ }^{6-9}$ A. glandulosa is frequently used in tea form by local populations in Brazil. Information obtained from an ethnopharmacologic survey administered to local populations confirms the traditional use of the leaves and aerial parts of this plant in tea form. ${ }^{7}$ In addition, scientific studies have shown that the leaves of A. glandulosa are commonly used in infusions in folk medicine, and infusions extract primarily polar compounds present in the medicinal plants. ${ }^{10}$ Moreover, studies have reported anti-inflammatory activities of $A$. castaneifolia and $A$. cordifolia, other species from Alchornea genus that are used in folk medicine to treat inflammation in different countries. ${ }^{11-13}$

Angiogenesis results from multiple signals acting on endothelial cells. These cells form the inner layer of blood vessels and are surrounded by pericytes that regulate the function of the blood vessels. Regulation of the barrier function 
by endothelial cells is an intricate process, requiring coordination of numerous, complex signaling pathways involved in blood vessel development and inflammatory responses. ${ }^{14}$

It has become increasingly clear that inflammation is a key component in tumor insurgence. ${ }^{15}$ Inflammation occurs in response to host injury or infection, as the result of an autoimmune disease, or in response to the development of a tumor. Although the immune system may help fight the tumor, it may also increase the tumorigenic process. In fact, recent data suggest a strong link between chronic inflammation, angiogenesis, and the development of cancer. ${ }^{16}$

Chronic inflammation plays a complex position in carcinogenesis. Evidence suggests that persistent inflammation functions as a driving force in the journey to cancer. Overexpression, elevated secretion, or abnormal activation of proinflammatory mediators, such as cytokines, chemokines, cyclooxygenase-2, prostaglandins, inducible nitric oxide (NO) synthase, NO, and a distinct network of intracellular signaling molecules (including upstream kinases and transcription factors), facilitate tumor promotion and progression. Many proinflammatory mediators, especially cytokines, chemokines, and prostaglandins, turn on the angiogenic switches mainly controlled by vascular endothelial growth factor (VEGF), thereby inducing inflammatory angiogenesis and tumor cell-stroma communication. This will result in tumor angiogenesis, metastasis, and invasion. ${ }^{17}$ Furthermore, approximately $15 \%-20 \%$ of all malignancies are initiated or exacerbated by inflammation, confirming that initiation and progression of cancer are closely linked to angiogenesis. ${ }^{18}$

On the basis of the relationship between inflammation and angiogenesis, we decided to evaluate the potential of $A$. glandulosa fraction (AGF) in the control of angiogenesis, a complex multistep process that consists of proliferation, migration, and anastomosis of endothelial cells and has a major role in the development of pathologic conditions, such as inflammatory diseases, tumor growth, and metastasis. Accordingly, the present study addressed cell viability, proliferation, apoptosis, invasion, and formation of capillary-like structures in endothelial cell cultures. Moreover, knowing that nuclear factor $-\kappa \mathrm{B}(\mathrm{NF} \kappa \mathrm{B})$ signaling pathway is involved in all these cell processes, we investigated whether the mechanism of AGF antiangiogenic activity relies on this transcription factor $\mathrm{NF} \kappa \mathrm{B}$ signaling pathway.

\section{MATERIALS AND METHODS}

\section{Plant material}

The leaves of A. glandulosa Poepp \& Endl. (Euphorbiaceae) were collected in the Biological Reserve and Experimental Station at Mogi Guaçu, São Paulo State, Brazil, in March 2005, and a voucher specimen (SP319257) has been deposited in the herbarium of the Botanic Institute (São Paulo, Brazil).

\section{Phytochemical procedures}

The shade-dried leaves $(1.5 \mathrm{~kg})$ of A. glandulosa were ground and defatted with $n$-hexane $(3.5 \mathrm{~L} \times 3$, at room temperature) and exhaustively extracted by maceration with methanol $(4.2 \mathrm{~L} \times 3$, at room temperature). The methanol extract was concentrated under reduced pressure to yield $3.8 \mathrm{~g}$ of a syrup residue. The concentrate was then diluted with methanol:water $(4: 1,700 \mathrm{~mL})$ and partitioned with ethyl acetate $(3 \times 700 \mathrm{~mL})$. After solvent was removed by using a rotary evaporator, ethyl acetate fraction yield $2.5 \mathrm{~g}$, which was labeled AGF.

\section{Isolation and identification of compounds from AGF}

The AGF (1 g) was chromatographed by gel permeation over Sephadex LH-20 $(180 \times 4 \mathrm{~cm})$ eluted with methanol to yield 10 subfractions (AGF-1-AGF-10). Chromatographic purification of subfractions AGF-2 and AGF-3 $(190 \mathrm{mg})$ by reverse-phase high-performance liquid chromatography (RP-HPLC) ( $\mathrm{MeOH}: \mathrm{H}_{2} \mathrm{O}, 1: 4$; ultraviolet detection at $272 \mathrm{~nm}$; flow rate, $10 \mathrm{~mL} / \mathrm{min}$ ), affording compounds 1 (76 mg) and $2(64 \mathrm{mg})$. Subfractions AGF-4 and AGF-5 (206 mg) were further purified by RP-HPLC $\left(\mathrm{MeOH}: \mathrm{H}_{2} \mathrm{O}\right.$, 3:2; ultraviolet detection at $254 \mathrm{~nm}$; flow rate, $12 \mathrm{~mL} / \mathrm{min}$ ), furnishing compounds 3 (72 mg), 4 (32 mg), and 5 (36 mg). Subfractions AGF-6-AGF-10 were checked by thin-layer chromatography on silica gel eluted with the following mixture: ethyl acetate:water:formic acid:acetic acid (100:27:11:11). Chromatography indicated that it was pure and led to its identification as compound $6(324 \mathrm{mg})$. Thus, on the basis of nuclear magnetic resonance (NMR) ${ }^{1} \mathrm{H}$ and ${ }^{13} \mathrm{C}$ NMR data analysis, the structures of compounds $1-6$ were identified as protocatechuic acid, ${ }^{19}$ methyl gallate, ${ }^{20}$ isoquercitrin, ${ }^{21}$ isovitexin, ${ }^{22,23}$ rutin, ${ }^{21}$ and corilagin, ${ }^{24}$ respectively (Fig. 1).

\section{Preparation of AGF samples}

AGF was dissolved in dimethyl sulfoxide (DMSO) and added to cell culture M199 medium at a concentration of $50 \mu \mathrm{g} / \mathrm{mL}$ established according to 3-(4,5-dimethylthiazol2-yl)-2,5-diphenyltetrazolium bromide (MTT) assays. This concentration was chosen on the basis of a concentration curve viability assay in human umbilical vein endothelial cells (HUVEC) (Fig. 2) and is in agreement with previous studies we performed in macrophage cultures established according to MTT assays (data not shown). AGF was added to serum-free M199 medium containing endothelial cell growth supplement for 24 hours. Control cells were incubated with M199 medium and 0.1\% DMSO (vehicle). DMSO concentration was $0.1 \%$ in every culture.

\section{Culture of HUVEC}

HUVEC were obtained from ScienceCell Research Labs. HUVEC were cultured in M199 medium (Sigma-Aldrich) supplemented with $20 \%$ fetal bovine serum (Invitrogen Life Technologies), $1 \%$ penicillin/streptomycin (Invitrogen Life Technologies), $0.01 \%$ heparin (Sigma-Aldrich), and $30 \mu \mathrm{g} /$ $\mathrm{mL}$ endothelial cell growth supplement (Sigma-Aldrich) and were maintained at $37^{\circ} \mathrm{C}$ in a humidified $5 \% \mathrm{CO}_{2}$ atmosphere. Cells were used between passages 3 and 8 and 


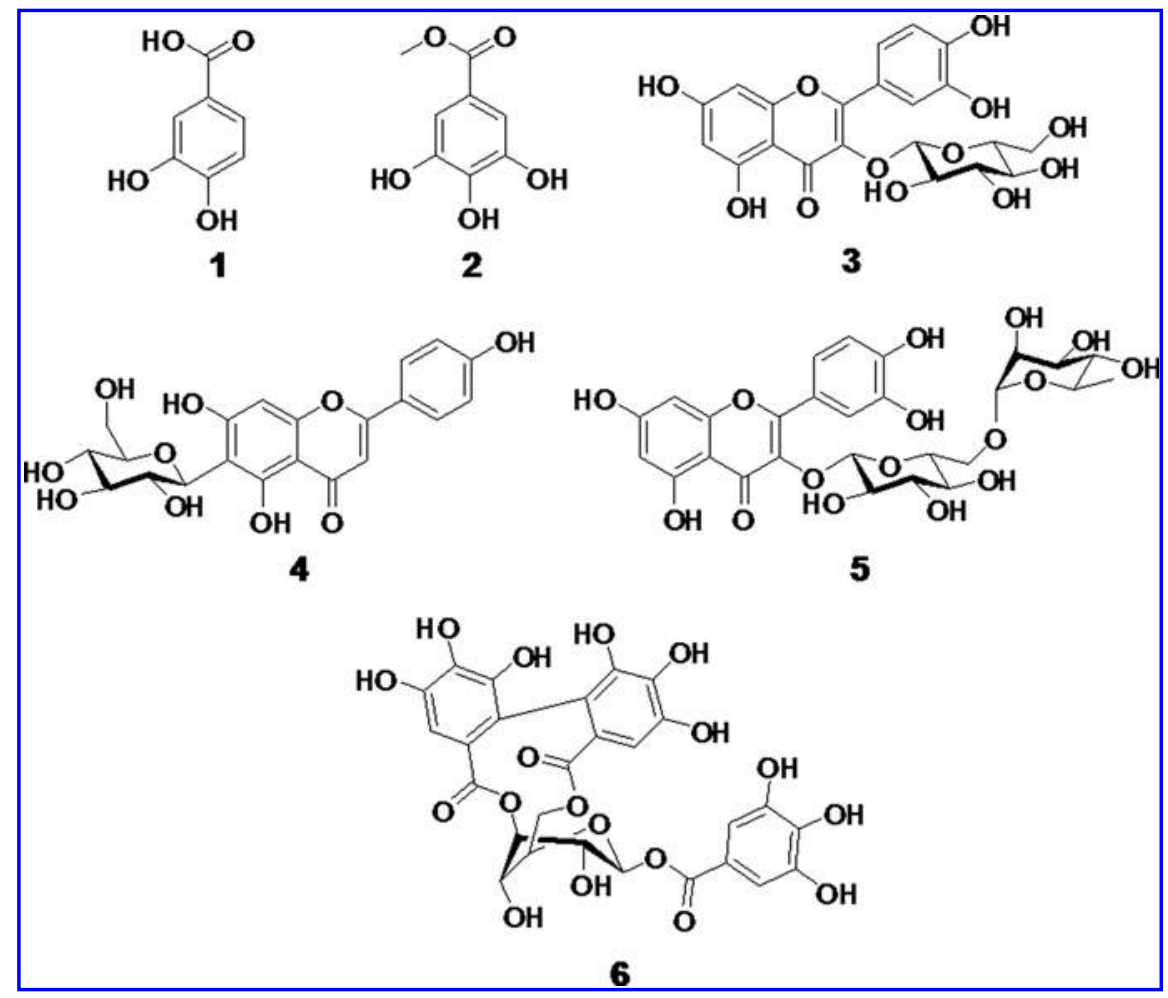

FIG 1. Molecular structures of the major compounds 1-6 isolated from ethyl acetate fraction obtained from Alchornea glandulosa. were seeded on plates coated with $0.2 \%$ gelatin (Sigma) and allowed to grow.

\section{MTT Assay}

HUVEC were allowed to grow until 70\%-90\% confluence and were then incubated with different concentrations of AGF $(50 \mu \mathrm{g} / \mathrm{mL}, 100 \mu \mathrm{g} / \mathrm{mL}, 200 \mu \mathrm{g} / \mathrm{mL}$, and $400 \mu \mathrm{g} / \mathrm{mL})$ and M199 medium (control) for 24 hours. After the incubation period, cells were washed twice with phosphatebuffered saline and subjected to MTT assay as described by Mosmann. ${ }^{25}$ After incubation, the formazan formed was dissolved in DMSO and the optical density was measured by using a microplate reader (Multiskan) equipped with a 540$\mathrm{nm}$ filter and 660-nm reference filter. The optical density of dissolved formazan in the control was taken as $100 \%$ of viability.

\section{Bromodeoxyuridine proliferation assay}

HUVEC $\left(5 \times 10^{4}\right)$ were cultured by following standard conditions or the treatment procedures for 24 hours. Cells were then washed twice with phosphate-buffered saline and subjected to in situ detection with bromodeoxyuridine (BrdU), an index of DNA synthesis and cell proliferation. Cells were incubated with BrdU solution at a final concentration of $0.01 \mathrm{mM}$ for 24 hours. The in situ detection was then performed by using a BrdU In Situ Detection Kit (BD Biosciences Pharmingen) according to the manufacturer's instructions. The results are presented as mean \pm standard deviation and are expressed as percentage of proliferating cells. The percentage of proliferating cells was evaluated at a $200 \times$ magnification field. A total of 1,000 nuclei were evaluated. Five independent experiments were performed.

Terminal deoxynucleotidyl transferase-mediated deoxyuridine triphosphate nick-end labeling assay

Cells $\left(2 \times 10^{4}\right)$ plated in glass coverslips were grown for 24 hours and then incubated with $50 \mu \mathrm{g} / \mathrm{mL}$ AGF or $0.1 \%$

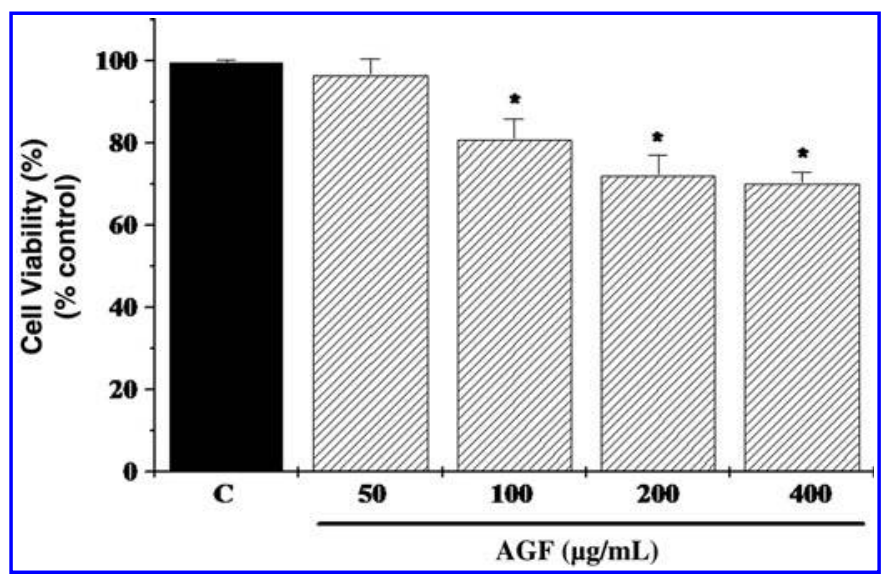

FIG 2. Effect of different concentrations of Alchornea glandulosa on the viability of human umbilical vein endothelial cells (HUVEC) evaluated by 3-(4,5-dimethylthiazol-2-yl)-2,5-diphenyltetrazolium bromide assay. Results are expressed as percentage of control cells. Bars represent mean \pm standard deviation. Assays were repeated 5 times and were performed in duplicate. The number of viable cells did not significantly differ between $50 \mu \mathrm{g} / \mathrm{mL}$ AGF-treated and control cells. $* P<.01$ compared with control. AGF, Alchornea glandulosa ethyl acetate fraction. 
DMSO M199 medium (control) for 24 hours. Terminal deoxynucleotidyl transferase-mediated deoxyuridine triphosphate nick-end labeling (TUNEL) assay was performed by using the In Situ Cell Death Detection kit (Roche Diagnostics) according to the manufacturer's instructions. ${ }^{26,27}$ Apoptosis was determined as the percentage of positive cells per 1,000 4',6-diamidino-2-phenylindole-stained nuclei. Glass coverslips were visualized under a fluorescence microscope (Nikon Eclipse 50i) at a magnification of $200 \times$.

\section{Invasion assay}

The invasive capacity of HUVEC was evaluated in vitro in the presence of AGF using a double-chamber assay by measuring the number of cells that invaded Transwell BD-Matrigel basement membrane matrix inserts (BDBiosciences), in accordance with the manufacturer's instructions. Fetal bovine serum was used as a chemoattractant agent. The ratio between invading cells in AGFtreated cultures and those in control cultures (untreated cells) for the same initial amount of cells was then observed.

\section{Matrigel assay: tube formation index}

To examine the ability of cells to assemble into capillarylike structures, growth factor-reduced Matrigel (GFRMatrigel; BD Biosciences)-coated plates were used. In brief, cells were cultured on GFR-Matrigel-coated plates for 24 hours in the presence of $50 \mu \mathrm{g} / \mathrm{mL}$ AGF or $0.1 \%$ DMSO M199 medium (control). The number of tubule-like structures was then quantified, and photomicrographs were taken by using an inverted microscope (400× magnification). Each cord fragment between the ramifications was considered 1 cord unit. Results are mean values obtained by evaluating the whole cultures of each well subjected to the same treatment. A semi-quantitative measurement of cord formation in GFR-Matrigel cultured HUVEC was performed (tube formation index) as described elsewhere. $^{28}$

\section{$N F \kappa B$ activity}

$\mathrm{NF} \kappa \mathrm{B}$ activity was determined by enzyme-linked immunosorbent assay. HUVEC lysates were obtained and quantified by a bicinchoninic acid protein assay kit (Pierce). $\mathrm{NF} \kappa \mathrm{B}$ activity was measured by using a Trans $\mathrm{AM} \mathrm{NF} \kappa \mathrm{B}$ p50 transcription factor assay kit (Active Motif). In brief, protein samples $(20 \mu \mathrm{g})$ were added to a 96-well plate with immobilized oligonucleotide containing the $\mathrm{NF} \kappa \mathrm{B}$ consensus site. Sample wells were incubated with $\mathrm{NF} \kappa \mathrm{B}$ p50 subunit primary antibody, followed by incubation with horseradish peroxidase-conjugated secondary antibody. Quantification was performed at $450 \mathrm{~nm}$ and $650 \mathrm{~nm}$ by using a plate reader (Multiskan Ascent; Thermo Electron Corp.).

\section{Statistical analysis}

All experiments were performed in triplicate. Quantifications are expressed as mean \pm standard deviation of 5 in- dependent experiments and are expressed as percentage of control, which was considered to be $100 \%$. Statistical significance of the difference between 2 groups was evaluated by 1-way analysis of variance, followed by the Dunnet test using GraphPad Instat 3.05. A difference between experimental groups was considered statistically significant when the $P$ value was less than .01 .

\section{RESULTS}

\section{Effects of AGF in HUVEC}

To evaluate whether AGF exerted any cytotoxic effect on endothelial cells, HUVEC were cultured until $90 \%$ confluency and then incubated with different concentrations of AGF $(50 \mu \mathrm{g} / \mathrm{mL}, 100 \mu \mathrm{g} / \mathrm{mL}, 200 \mu \mathrm{g} / \mathrm{mL}$, and $400 \mu \mathrm{g} / \mathrm{mL})$. Cell viability was assessed by the MTT test. These experiments were performed in highly confluent cell cultures, which present an already slow replication rate. This ensures that the possible toxic effect is not masked by the effects of these agents on cell proliferation, apoptosis, or migration behavior. However, the highest percentage of cell viability $(96.58 \% \pm 3.88 \%)$ was observed after 24-hour incubation with AGF at $50 \mu \mathrm{g} / \mathrm{mL}$ (Fig. 2). On the basis of this excellent viability level, the $50-\mu \mathrm{g} / \mathrm{mL}$ concentration of AGF was established and used for all in vitro assays.

The effect of AGF on cell proliferation and apoptosis was next evaluated at lower confluent cell cultures. We observed a 1.7-fold decrease in the percentage of proliferating cells $(60.82 \pm 9.63 ; P<.01$ compared with control) (Fig. 3a) and a relevant increase (19-fold) in the percentage of apoptotic cells $(1956.14 \% \pm 114.00 \% ; P<.01$ compared with control) (Fig. 3b) after incubation with AGF at $50 \mu \mathrm{g} / \mathrm{mL}$, as evaluated by BrdU and TUNEL assays, respectively.

Angiogenesis also requires migration and invasion of endothelial cells. Subsequently, we investigated whether AGF affected the migration and invasion capacity of HUVEC by using a double-chamber assay. As illustrated in Figure $3 \mathrm{c}, 50 \mu \mathrm{g} / \mathrm{mL}$ AGF resulted in a strong reduction in the migratory capacity of $\operatorname{HUVEC}(13.74 \% \pm 5.15 \% ; P<.01$ compared with control).

\section{Effects of AGF on cord-like structures formed by HUVEC}

To form a new blood vessel, endothelial cells must assemble into vascular capillary structures. HUVEC formed highly branched capillary-like structures when cultured on GFR-Matrigel. Therefore, we next examined whether AGF affected the development of these structures. Incubation of HUVEC with M199 medium and 0.1\% DMSO (control) for 24 hours led to the formation of very ramified cord-like structures. However, the presence of AGF led to a drastic reduction in the number of these cord-like structures to $0.4 \% \pm$ $0.55 \%$ of control values $(P<.01$ compared with control).

Ramifications almost disappeared when HUVEC were treated with AGF in comparison with control, and only undifferentiated round cells could be seen under the mi- 

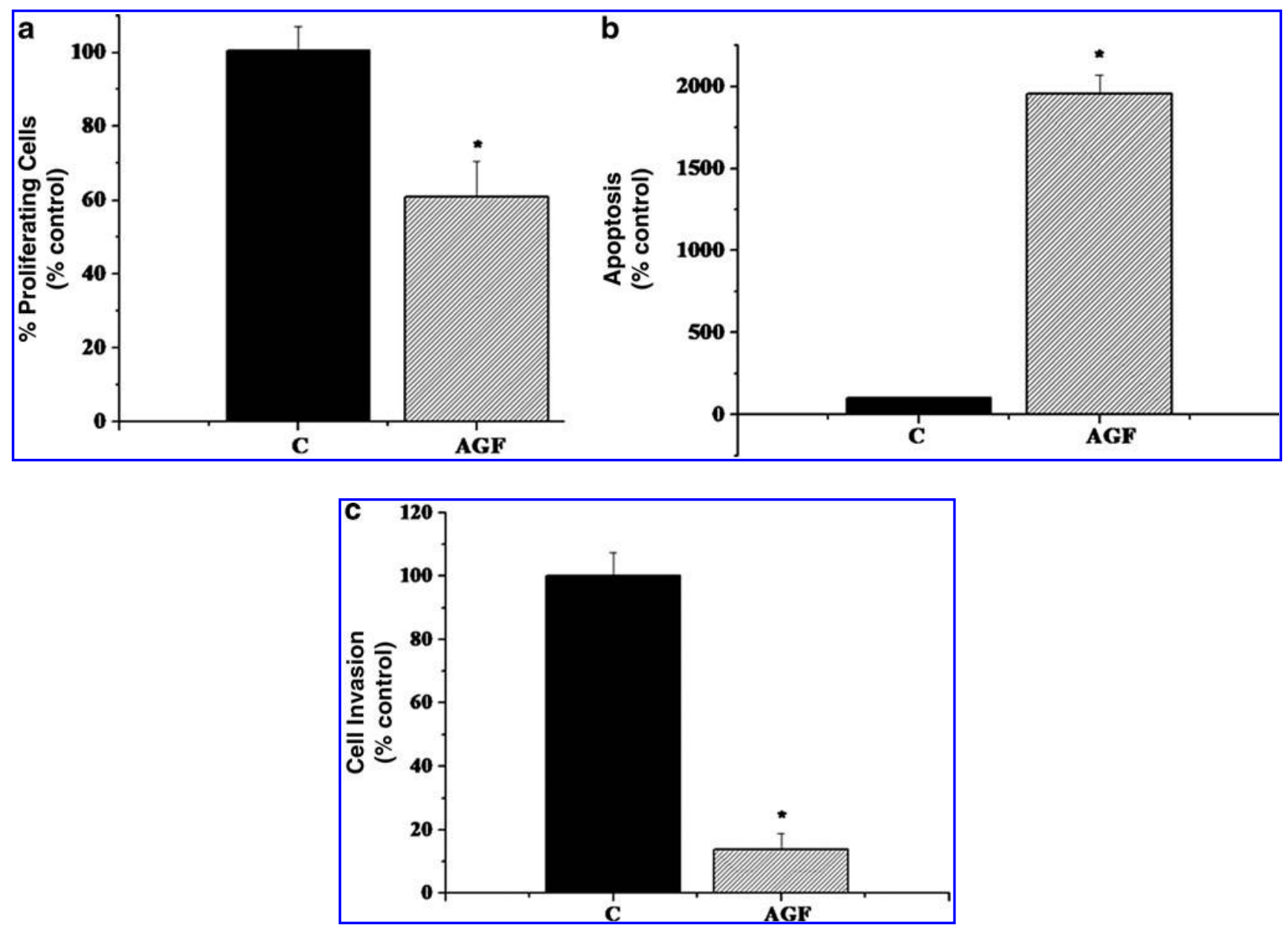

FIG 3. Effect of Alchornea glandulosa fraction (AGF) on proliferation, apoptosis, and migration capacity of human umbilical vein endothelial cells (HUVEC). (a) Cell proliferation levels assessed by bromodeoxyuridine assay. Assays were repeated 5 times and performed in triplicate. $* P<.01$ compared with control. (b) Effect of AGF on apoptosis of HUVEC by terminal deoxynucleotidyl transferase-mediated deoxyuridine triphosphate nick-end labeling (TUNEL) assay. The percentage of apoptotic cells was evaluated by the ratio between TUNEL-stained cells and 4',6-diamidino-2-phenylindole-stained nuclei in every culture. Results are expressed as percentage of control cells. Bars represent mean \pm standard deviation. Assays were repeated 5 times and performed in triplicate. ${ }^{*} P<.01$ compared with control. (c) Effect of AGF on invasive capacity of HUVEC by double-chamber assay. Bars represent the percentage of invading cells relative to the initial number of cells cultured. Results are expressed as percentage of control cells. Assays were repeated 5 times and performed in triplicate. $* P<.01$ compared with control. C, control.

croscope. These findings indicate that the fraction inhibited vessel assembly, a crucial feature for the angiogenic process (Fig. 4a and 4b).

\section{AGF inhibited $N F \kappa B$ activity in HUVEC}

$\mathrm{NF} \kappa \mathrm{B}$ is a transcription factor that is activated in response to various inflammatory stimuli. The antiangiogenic effects observed in HUVEC prompted us to use the using $\mathrm{NF} \kappa \mathrm{B}$ ELISA assay to examine whether the fraction affected the activity of this factor. A significant reduction in $\mathrm{NF} \kappa \mathrm{B}$ p50 subunit activity $(43.33 \% \pm 3.41 \% ; P<.01$ compared with control) was found in HUVEC after incubation with AGF, indicating that $\mathrm{NF} \kappa \mathrm{B}$ signaling inactivation is a pathway triggered by this fraction (Fig. 5).

\section{DISCUSSION}

The enormous botanical diversity in Brazil facilitates the development of novel ethical drugs for the treatment of diseases in humans. ${ }^{29}$ Botanical immunomodulators and botanical products that influence pathways of angiogenesis, apoptosis, and cell signaling in vitro have stimulated research interest and may expand the variety of cancer treatments. ${ }^{30}$

Angiogenesis imbalance is a major contributor of numerous malignant, ischemic, inflammatory, infectious, and immune disorders. ${ }^{31}$ In this study we successfully used HUVEC to show that AGF possesses antiangiogenic activity in several in vitro assays. The fact that endothelial cells are the main players in the angiogenesis process renders them 


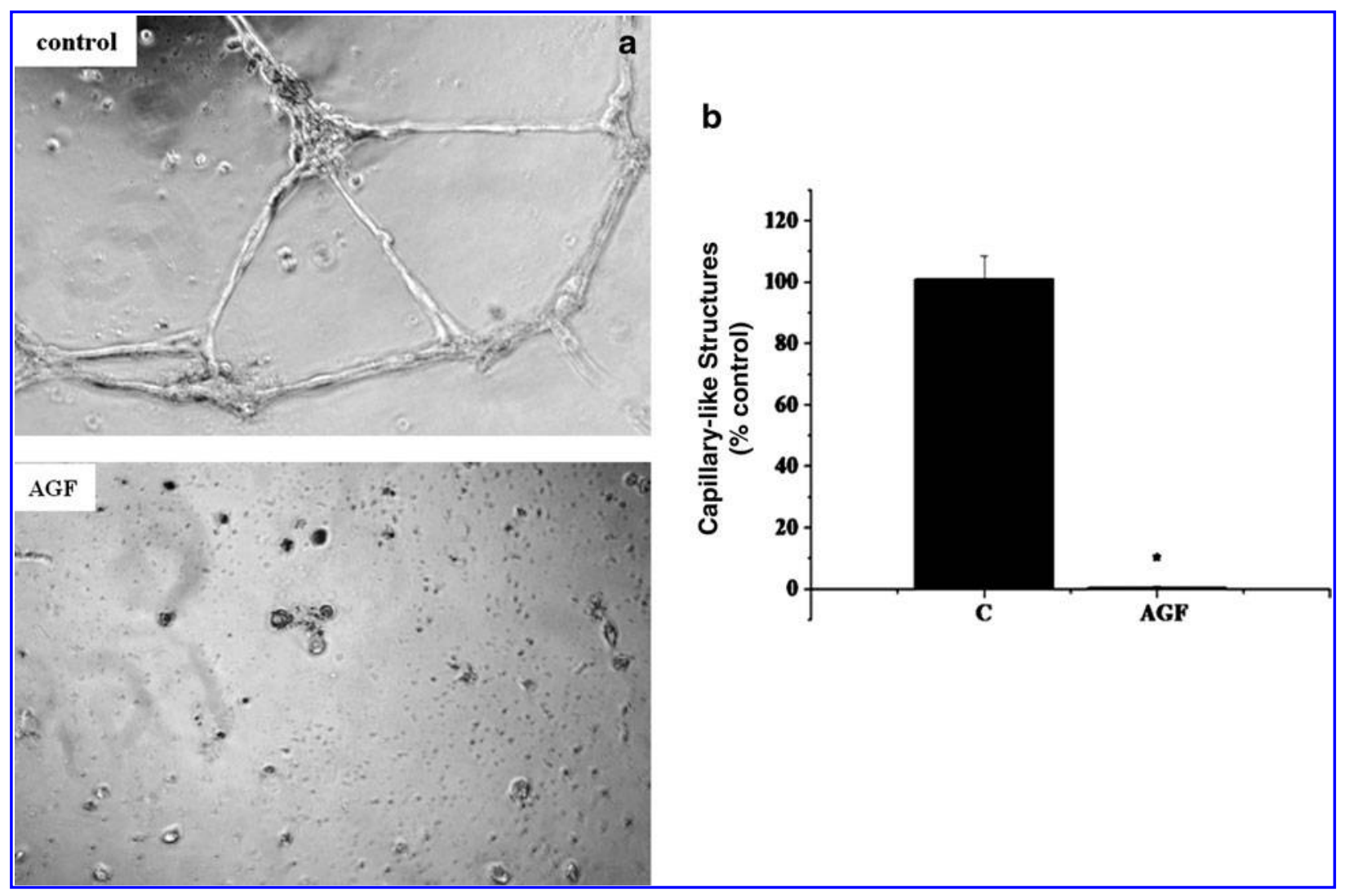

FIG 4. Effects of Alchornea glandulosa fraction (AGF) on assembly of capillary-like structures. (a) Photomicrographs of capillary-like structures assembly in human umbilical vein endothelial cells (HUVEC) cultures after treatment with AGF. In contrast to control cells, incubation with $50 \mu \mathrm{g} / \mathrm{mL}$ AGF resulted in absence of ramifications with undifferentiated cells. Photomicrographs are representative of the whole cultures. Every culture was established in triplicate and visualized under an inverted microscope (400× magnification). (b) Semiquantification of the tube formation index in HUVEC after incubation with $50 \mu \mathrm{g} / \mathrm{mL}$ AGF. The number of capillary-like structures formed was drastically reduced upon incubation with this fraction. Bars correspond to the percentage of the number of tubule-like structures compared with control (mean \pm standard deviation). $* P<.01$ compared with control.

putative peculiar targets for antiangiogenic therapy: They possess nontransforming characteristics, have easy accessibility to achievable concentrations of antiangiogenic agents, and are unlikely to acquire drug resistance. ${ }^{32}$ Vascular endothelial cells constitute first-line exposure to blood-borne agents. Thus, it is plausible that antiangiogenic activity of phytochemicals could be associated with reducing cancer risk by preventing the growth and metastasis of tumor. ${ }^{33}$

In the first part of this study, we observed that AGF induced an approximately 1.7 -fold decrease in the percentage of endothelial cell proliferation and a 19-fold increase in apoptotic rate as compared with controls (Fig. 3a and 3b). In addition, the invasive behavior of endothelial cells is another mainstay in angiogenesis, and invasive capacity requires extracellular matrix degradation. The latter involves the activation of many endothelial cell signaling pathways. Our findings show a very effective decrease in Matrigel invasion in AGF-treated HUVEC. AGF was at least 7 times as potent as control in inhibiting the migratory capacity of HUVEC (Fig. 3c). Proliferation and migration of endothelial cells appears to be at least partially dependent on distinct pathways in endothelial cells. Józkowicz et al., ${ }^{34}$ for instance, showed that VEGF-induced migration but not proliferation of HUVEC relies on the production of NO, released by the activated endothelial NO synthase.

In the second part of this study, the antiangiogenic activity of AGF was further established by tube formation assay performed on GFR-Matrigel. We proved that AGF prevented endothelial cell tubulogenesis when cultured on Matrigel. Remarkably, network-like structures were not found when HUVEC were incubated with AGF, and just isolated cells were observed under the inverted microscope, indicating that AGF can strongly disrupt tube formation (Fig. 4a and 4b). It is already known that angiogenesis process could be considered an important target to suppress tumor growth and metastasis because tumor angiogenesis is critically important for the growth of solid tumors. ${ }^{32}$ Moreover, therapeutic inhibition of vessel formation could be best suited for preventive strategies aimed at suppressing angiogenesis in primary tumors in patients at risk for mi- 


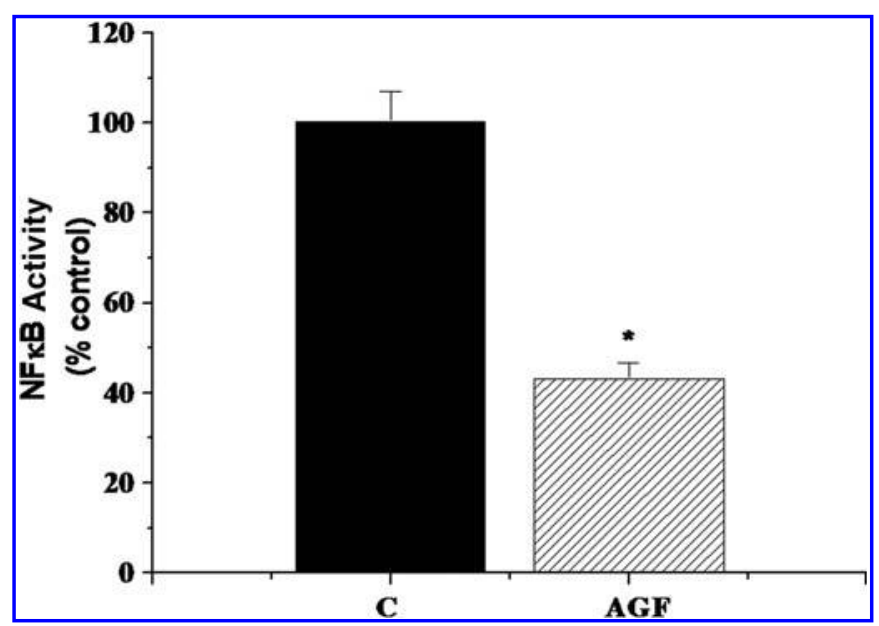

FIG 5. Effects of Alchornea glandulosa (AGF) on activation of nuclear factor $\kappa \mathrm{B}$ p50 subunit in human umbilical vein endothelial cells (HUVEC) nuclear factor $\kappa \mathrm{B}$ p p50 subunit activity was significantly reduced in HUVEC treated with $50 \mu \mathrm{g} / \mathrm{mL}$ AGF versus control. Results are mean \pm standard deviation of 5 independent experiments performed in triplicate. $* P<.01$ compared with control. $\mathrm{NF} \kappa \mathrm{B}$, nuclear factor $\kappa \mathrm{B}$.

crometastases after surgical removal of a primary tumor. ${ }^{35}$ Consequently, given the strong dependence of cancer in angiogenesis, our findings led us to propose that AGF can inhibit tumor growth through the suppression of blood vessel development, exhibiting potential antitumor properties.

Investigators recently reported that many plants can act as angiogenesis inhibitors. Yoo et al..$^{36}$ observed that ethanol extract prepared from the aerial parts of Saururus chinensis, a plant used to treat edema and inflammatory diseases in Oriental folk medicine, possesses potent antiangiogenic and antinociceptive activities as well as anti-inflammatory activity, which partly supports its therapeutic efficacy. As was seen with AGF, different chemopreventive phytochemicals target various components of angiogenesis, including angiogenic signaling. These chemopreventive agents would be convenient to use because they are mostly nontoxic natural compounds and could be part of the daily diet. ${ }^{32}$

Shiraia bambusicola, a Chinese plant, has long been used in rheumatoid arthritis treatment, a disease in which angiogenesis plays an important role. Tong et al. ${ }^{37}$ reported that Shiraiachrome A isolated from S. bambusicola significantly inhibited the proliferation, migration, and tube formation of human microvascular endothelial cells. In addition, Shiraiachrome A inhibited the formation of new microvessels in a rat aorta culture model, as well as in the chick embryo chorioallantoic membrane assay. These researchers also demonstrated that this compound suppressed autophosphorylation of 4 receptor tyrosine kinases, thereby inhibiting angiogenesis. These findings indicate that this compound may be a potent therapeutic agent for vasculoproliferative diseases, such as cancer, rheumatoid arthritis, and diabetic retinopathy.
Dahuang is often included as an ingredient in traditional Chinese compound prescriptions for the treatment of inflammatory diseases. This application may be mediated through antiangiogenesis and thus would shed light on its potential value in cancer therapy. He et al. ${ }^{38}$ tested the inhibitory effects of different fractions and a series of anthraquinone derivatives against vessel formation in zebrafish embryos. Ethyl acetate fraction at $20 \mu \mathrm{g} / \mathrm{mL}$ showed the strongest inhibition of vessel formation$52 \%$ - and 3 anthraquinones (aloe-emodin, emodin, and rhein) displayed potent antiangiogenic activities. The authors believe that the angiogenic properties of rhubarb root may partly account for its use in inflammatory diseases.

Altogether, our findings showed that treatment with AGF affected several processes within endothelial cells. These findings prompted us to examine whether AGF had any effect on $\mathrm{NF} \kappa \mathrm{B}$ activity. NF $\kappa \mathrm{B}$ is a transcription factor activated in response to various inflammatory stimuli, such as cytokines; growth factors; hormones; mitogens; carcinogens; chemotherapeutic agents; viral products; eukaryotic parasites; endotoxin; fatty acids; metals; radiation; hypoxia; and psychological, physical, oxidative, and chemical stresses. In addition, constitutively active $\mathrm{NF} \kappa \mathrm{B}$ is frequently encountered in a wide variety of tumors. Furthermore, $\mathrm{NF} \kappa \mathrm{B}$ activation regulates the expression of over 400 genes. Therefore, because of the critical role $\mathrm{NF} \kappa \mathrm{B}$ plays in the pathogenesis of cancer, specific inhibitors of this factor are being sought. Agents that prevent cancer or inflammation have been found to suppress $\mathrm{NF} \kappa \mathrm{B}$ activation. Numerous reports indicate that ancient plants and their components are potent as $\mathrm{NF} \kappa \mathrm{B}$ inhibitors. ${ }^{39}$

In the current study, AGF inhibited endothelial $\mathrm{NF} \kappa \mathrm{B}$ p50 subunit activity (Fig. 5), suggesting that inactivation of $\mathrm{NF} \kappa \mathrm{B}$ by the fraction is probably one of the mechanisms involved in the observed antiangiogenic effects on HUVEC. This is a crucial finding given the role of $\mathrm{NF} \kappa \mathrm{B}$ in activating inflammatory and antiapoptotic genes transcription, 2 processes associated with angiogenesis. ${ }^{40}$ In addition, antiinflammatory agents that suppress $\mathrm{NF} \kappa \mathrm{B}$ should have a potential role in both the prevention and the treatment of cancer. $^{41}$

It is meaningful that endothelial cells are not the only possible target for antiangiogenic therapy or prevention of vascularization (angioprevention). Emerging evidence reveals that native immune cells recruited into tumors stimulate endothelium and are responsible for an indirect pathway of tumor vascularization. ${ }^{42}$ Previous research from our group demonstrates that AGF can act in macrophage cells by inhibiting hydrogen peroxide, NO, and tumor necrosis factor- $\kappa$ production, and, accordingly, show a therapeutic potential in the control of inflammatory disorders. ${ }^{8}$ In agreement, various plants present antiangiogenic effects in addition to anti-inflammatory activity and inhibitory action on NO production. ${ }^{43,44}$

Moreover, He et al $^{45}$ confirmed that inflammation inhibitors may have angiogenesis-inhibiting capacity. Tripterygium wilfordii, a plant used to treat immuneinflammatory diseases in China, and its terpenoids, partic- 
ularly triptolide, are potent angiogenesis inhibitors with potential application against angiogenesis in cancer treatment. These authors observed that angiopoietin 2/tie2 signaling pathway may play an important role in triptolideinduced antiangiogenesis. The ethyl acetate partition from ethanol extract of $T$. wilfordii has been subjected to a phase II double-blind clinical trial and was shown to have beneficial effects. ${ }^{46,47}$

Our study identified 6 compounds from AGF: protocatechuic acid, methyl gallate, isoquercitrin, isovitexin, rutin, and corilagin (Fig. 1). Among these compounds, protocatechuic acid and rutin may be involved with angiogenesis, especially with VEGF. It is important to mention that among many known growth factors, VEGF appears to play a pivotal role in the angiogenic process; it is involved in a variety of normal and pathologic processes. ${ }^{27,28}$

Protocatechuic acid, a copper chelator, has potential for the treatment of copper-overload disease (Wilson's disease). ${ }^{48}$ Sen et al. ${ }^{49}$ observed that protocatechuic acid treatment inhibited $\mathrm{H}_{2} \mathrm{O}_{2}$-induced VEGF expression. The authors suggest that copper may play a role in mediating the stimulatory effect of $\mathrm{H}_{2} \mathrm{O}_{2}$ on inducible VEGF expression.

Schindler and Mentlein ${ }^{50}$ investigated the effects of rutin on the release of VEGF from breast and brain tumor cells. In that study, rutin was one of the most potent inhibitors of VEGF release. The authors believe that rutin accumulates in the cell surface and thereby interacts with lipid constituents of biomembranes. The modification of membrane receptor and enzyme activities as well as antioxidant effects might both influence signal transduction pathways.

Although protocatechuic acid and rutin are present in AGF, it is remarkable to consider that natural products such as the fraction we studied could contain a range of complex organic chemicals that may work on multiple targets and may have synergistic activity. Acting through multiple pathways is a potential advantage because these natural products can reduce the development of resistance by cancer cells. ${ }^{51}$ Moreover, they may inhibit angiogenesis by interacting with numerous pathways and by affecting cell signaling, the apoptotic pathway, and the interaction of cancer cells with the immune system. Some researchers hypothesize that angiogenesis within the tumour microenvironment may be more sensitive to a cocktail of natural health products administered continuously at relatively low doses than to single-agent pharmaceutical compounds administered intermittently at higher doses. In general, as compared with normal tissues, tumors contain very immature blood vessels that may be relatively more susceptible to antiangiogenic therapies, permitting a therapeutic gain. ${ }^{52,53}$

In conclusion, our study indicates that AGF, a fraction obtained from a plant traditionally used in Brazilian folk medicine, exerts a wide range of inhibitory effects in angiogenesis. Namely, AGF acts in endothelial cells and prevents most of the angiogenic steps, including proliferation, invasion, and capillary-like structures formation, while increasing apoptosis. One probable mechanism for the AGF effects on angiogenesis is the reduction of $\mathrm{NF} \kappa \mathrm{B}$ activity, a well-established angiogenic and inflammatory factor. These observations imply that AGF may be a novel inhibitor of angiogenesis and could be a good candidate to treat disorders that involve excessive angiogenesis, such as chronic inflammation, diabetic retinopathy, endometriosis, and adiposity. AGF could also provide a new approach to target and prevent tumor angiogenesis by treatment with a natural agent with anti-inflammatory properties.

\section{ACKNOWLEDGMENTS}

This work was supported by FCT (POCI, FEDER and Programa Comunitário de Apoio), and grants from CAPES/ PDEE (BEX 1008/07-2) program, CNPq and ERAB, European Advisory Board (EA0641). The authors would also like to thank Fundação de Amparo à Pesquisa do Estado de São Paulo (FAPESP) for fundings from Biota-Fapesp Program (no. 03/02176-7).

\section{AUTHOR DISCLOSURE STATEMENT}

No competing financial interests exist.

\section{REFERENCES}

1. Heinrich M, Bremner P: Ethnobotany and ethnopharmacy: their role for anti-cancer drug development. Curr Drug Targets 2006;7:239-245.

2. Elisabetsky E, Wannmacher L: The status of ethnopharmacology in Brazil. J Ethnopharmacol 1993;38:137-143.

3. Duke J, Vasquez R: Amazonian Ethnobotanical Dictionary. CRC Press, Boca Raton, FL, USA, 1994, p. 677.

4. Tabarelli M, Mantovani W: Clareiras naturais e a riqueza de especies pioneiras em uma floresta Atlantica Montana. $\underline{\text { Rev Bras }}$ Biol 1999;59:239-251.

5. Taylor L: Herbal Secrets of the Rainforest. 2nd ed. Prima Publishing, Rocklin, CA, USA, 1998.

6. Lorenzi H: Árvores Brasileiras: Manual de Identificação e Cultivo de Plantas Arbóreas Nativas do Brasil. 4th ed. Instituto Plantarum, Nova Odessa, Brazil, 2002.

7. Silva EM, Hiruma-Lima CA, Lólis SF: Etnobotânica no município de Porto Nacional [abstract]. Symposium of Brazilian Medicinal Plants, UFMT-Cuiabá, Brazil, 2000, p. 106.

8. Lopes FC, Calvo TR, Vilegas W, Carlos IZ: Inhibition of hydrogen peroxide, nitric oxide and TNF-alpha production in peritoneal macrophages by ethyl acetate fraction from Alchornea glandulosa. Bio Pharm Bull 2005;28:1726-1730.

9. Calvo TR, Lima ZP, Silva JS, et al.: Constituents and antiulcer effect of Alchornea glandulosa: activation of cell proliferation in gastric mucosa during the healing process. Bio Pharm Bull 2007;30:451-459.

10. Santos FV, Calvo TR, Cólus IMS, Vilegas W, Varanda EA: Mutagenicity of two species of the genus Alchornea measured by Salmonella microsome assay and micronucleus test. Braz J Pharmacogn 2010;20:382-389.

11. Dunstan CA, Noreen Y, Serrano G, et al.: Evaluation of some Samoan and Peruvian medicinal plants by prostaglandin biosynthesis and rat ear oedema assays. J Ethnopharmacol 1997;57: $35-56$. 
12. Osadebe PO, Okoye FB: Anti-inflammatory effects of crude methanolic extract and fractions of Alchornea cordifolia leaves. $\underline{J}$ Ethnopharmacol 2003;89:19-24.

13. Mavar-Manga $\mathrm{H}$, Haddad M, Pieters L, et al.: Anti-inflammatory compounds from leaves and root bark of Alchornea cordifolia (Schumach. \& Thonn.) Müll. Arg.. J Ethnopharmacol 2008;115: 25-29.

14. Imhof BA, Aurrand-Lions M: Angiogenesis and inflammation face off. Nat Med 2006;12:171-172.

15. Sogno I, Vannini N, Lorusso G, et al:: Anti-angiogenic activity of a novel class of chemopreventive compounds: oleanic acid terpenoids. Recent Results Cancer Res 2009;181:209-212.

16. Angelo LS, Kurzrock R: Vascular endothelial growth factor and its relationship to inflammatory mediators. Clin Cancer Res 2007;13:2825-2830.

17. Kundu JK, Surh YJ: Inflammation: gearing the journey to cancer. Mutat Res 2008;659:15-30.

18. Ono M: Molecular links between tumor angiogenesis and inflammation: inflammatory stimuli of macrophages and cancer cells as targets for therapeutic strategy. 1501-1506.

19. Flamini G, Antognoli E, Morelli E: Two flavonoids and other compounds from the aerial parts of Centaurea bracteata from Italy. Phytochemistry 2001;57:559-564.

20. Lee HL, Jeong HS: Isolation and identification of antimicrobial substance from Canavalia gladiata. Food Sci Biotechnol 2005; 14:268-274.

21. Regasini LO, Vellosa JCR, Silva DHS, et al.: Flavonols from Pterogyne nitens and their evaluation as myeloperoxidase inhibitors. Phytochemistry 2008;69:1739-1744.

22. Fernandes DC, Regasini LO, Vellosa JCR, et al.: Myeloperoxidase inhibitory and radical scavenging activities of flavones from Pterogyne nitens. Chem Pharm Bull 2008;56:723-726.

23. Leong CAN, Kinjo Y, Tako M, et al.: Flavonoid glycosides in the shoot system of Okinawa Tomu (Colocasia esculenta S.). Food Chem 2001;119:630-635.

24. Nawwar M, Hussein SAM, Merfort I: NMR spectral analysis of polyphenols from Punica granatum. Phytochemistry 1994;36: 793-798.

25. Mosmann T: Rapid colorimetric assay for cellular growth and survival: Application to proliferation and cytotoxicity assays. $\underline{J}$ Immunol Methods 1983;65:55-63.

26. Guerreiro S, Monteiro R, Martins MJ, et al.: Distinct modulation of alkaline phosphatase isoenzymes by 17 beta-estradiol and xanthohumol in breast cancer MCF-7 cells. Clin Biochem 2007;40:268-273.

27. Soares R, Guo S, Russo J, Schmitt FC: Role of the estrogen antagonist ICI182, 780 in vessel assembly and apoptosis of endothelial cells. Ultrastruct Pathol 2003;27:33-39.

28. Soares R, Balogh G, Guo S, et al.: Evidence for the notch signaling pathway on the role of estrogen in angiogenesis. $\underline{\mathrm{Mol}}$ Endocrinol 2004;18:2333-2343.

29. Balbani AP, Silva DH, Montovani JC: Patents of drugs extracted from Brazilian medicinal plants. Expert Opin Ther Pat 2009;19: 461-473.

30. Miller S, Stagl J, Wallerstedt DB, Ryan M, Mansky PJ: Botanicals used in complementary and alternative medicine treatment of cancer: clinical science and future perspectives. Expert Opin Invest Drugs 2008;17:1353-1364.
31. Carmeliet P: Angiogenesis in health and disease. Nat Med 2003;9:653-660.

32. Bhat TA, Singh RP: Tumor angiogenesis: a potential target in cancer chemoprevention. Food Chem Toxicol 2008;46:13341345 .

33. Singh RP, Agarwal R: Tumor angiogenesis: a potential target in cancer control by phytochemicals. Curr Cancer Drug Targets 2003;3:205-217.

34. Józkowicz A, Dulak J, Nigisch A, et al.: Involvement of nitric oxide in angiogenic activities of vascular endothelial growth factor isoforms. Growth Factors 2004;22:19-28.

35. Pfeffer U, Ferrari N, Morini M, et al.: Antiangiogenic activity of chemopreventive drugs. Int J Biol Markers 2003;18: 70-74.

36. Yoo HJ, Kang HJ, Jung HJ, et al.: Anti-inflammatory, antiangiogenic and anti-nociceptive activities of Saururus chinensis extract. J Ethnopharmacol 2008;120:282-286.

37. Tong Y, Zhang X, Zhao W, et al.: Anti-angiogenic effects of shiraiachrome A, a compound isolated from a Chinese folk medicine used to treat rheumatoid arthritis. Eur J Pharmacol 2004;494:101-109.

38. He ZH, He MF, SC Ma, But PP: Anti-angiogenic effects of rhubarb and its anthraquinone derivatives. J Ethnopharmacol 2009;121:313-317.

39. Ichikawa H, Nakamura Y, Kashiwada Y, Aggarwal BB: Anticancer drugs designed by mother nature: ancient drugs but modern targets. Curr Pharm Des 2007;13:3400-3416.

40. Soares R, Azevedo I: Inhibition of S1P by polyphenols prevents inflammation and angiogenesis: NFkappaB, a downstream effector? Free Radic Biol Med 2007;42:311.

41. Aggarwal BB, Shishodia S, Sandur SK, Pandey MK, Sethi G: Inflammation and cancer: how hot is the link? Biochem Pharmacol 2006;72:1605-1621.

42. Albini A, Tosetti F, Benelli R, Noonan DM: Tumor inflammatory angiogenesis and its chemoprevention. Cancer Res 2005;65: 10637-10641.

43. Ahn EK, Jeon HJ, Lim EJ, Jung HJ, Park EH: Anti-inflammatory and anti-angiogenic activities of Gastrodia elata Blume. $\underline{J \text { Eth- }}$ nopharmacol 2007;110:476-482.

44. Jeon HJ, Kang HJ, Jung HJ, et al.: Anti-inflammatory activity of Taraxacum officinale. I Ethnopharmacol 2008;115; 82-88.

45. He MF, Liu L, Ge W, et al.: Antiangiogenic activity of Tripterygium wilfordii and its terpenoids. J Ethnopharmacol 2009; 121:61-68.

46. Mao Y, Tao X, Lipsky PE: Pharmacokinetics of triptolide. Development and application of a high performace liquid chromatographic method for quantitation of triptolide in plasma. $J$ Liq Chromatogr Relat Technol 1999;9:1355-1366.

47. Ma J, Dey M, Yang H, et al.: Anti-inflammatory and immunosuppressive compounds from Tripterygium wilfordii. Phytochemistry 2007;68:1172-1178.

48. Kotsaki-Kovatsi VP, Vafiadou AJ, Koehler-Samuilidou G, Kovatsis A: Influence of 3,4-dihydroxybenzoic acid on metal ion concentrations in guinea pig tissues after copper intoxication. $\underline{\text { Vet }}$ Hum Toxicol 1997;39:211-214.

49. Sen CK, Khanna S, Venojarvi M, et al.: Copper-induced vascular endothelial growth factor expression and wound healing. $\underline{A m ~ J}$ Physiol Heart Circ Physiol 2002;282:H1821-1827. 
50. Schindler R, Mentlein R: Flavonoids and vitamin E reduce the release of the angiogenic peptide vascular endothelial growth factor from human tumor cells. J Nutr 2006;136: 1477-1482.

51. Sagar SM, Yance D, Wong RK: Natural health products that inhibit angiogenesis: a potential source for investigational new agents to treat cancer - Part 2. Curr Oncol 2006;13: 99-107.
52. Benjamin LE, Golijanin D, Itin A, Pode K, Keshet B: Selective ablation of immature blood vessels in established human tumors following vascular endothelial growth factor withdrawal. $\underline{J \text { Clin }}$ Invest 1999;103:159-165.

53. Eberhard A, Kahlert S, Goede V, et al.: Heterogeneity of angiogenesis and blood vessel maturation in human tumors: implications for antiangiogenic tumor therapies. Cancer Res 2000;60:1388-1393. 